\title{
Studies on the Legal Translation from the Perspective of Legal Pluralism*
}

\author{
Xia Dai \\ Southwest University of Political Science \& Law, Chongqing, China
}

\begin{abstract}
Legal pluralism has made certain theoretical development in the field of law, which has certain enlightenment on the concept and opinion of legal norms, legal system or order to the intercultural communication of legal culture. In addition to linguistics and translation field, the study of legal English should also make use of relevant legal theories to achieve beneficial interdisciplinary research. This paper focuses on the legal pluralism in the field of legal English and how to make innovative use of the theory. Facing the problems of "vacancy" and "dislocation" in Chinese legal translation, how to explore the nature of legal norms or the definition boundaries, and try to seek the enlightenment of the social system theory on legal translation.
\end{abstract}

Index Terms - legal pluralism, legal English, system theory

\section{INTRODUCTION}

The theoretical exploration of legal pluralism has attracted the attention of academic circles already, especially in the field of law. Relevant papers and monographs are blossomed in the theoretical discussion. Legal English, as a key branch of ESP, English for Specific Purpose, has gradually become an independent subject in the curriculum design of Chinese colleges and universities. Its growth must depend on the parallel development of legal theory and English theory, which also represents a strong indication that the interdisciplinary study in the field of legal English will definitely become the main trend. However, as far as the present situation in the China mainland is concerned, there are few studies on the application of legal pluralism theory to the field of legal English. This paper focuses on the enlightenment of legal pluralism to the study of legal English and how to realize the innovative application of legal pluralism theory. It probes into the nature of legal norms or their conceptual definition boundaries, and tries to seek the enlightenment of the social system theory on legal translation.

\section{The Proposal of Legal Pluralism}

Legal pluralism refers to the coexistence of two or more legal norms, legal systems or legal orders in the same social field. Initially, legal pluralism began with the use of research methods of legal anthropology and sociology of law, focusing on the analysis of the relationship between non-state order and state legal order (for example, the confrontation and integration of colonized areas and European legal system). In the 1980s, academic circles mainly concentrated on the study of "theoretical generalization" of "re-conceptualization of social-legal relations". Then in the 1990s, the traditional state-centered legal concept in the jurisprudence was challenged, and there were divergences between jurisprudence theorists and jurisprudence sociologists. The former upholds the general jurisprudence as the cornerstone of state law, takes national substantive law as the center, and emphasizes the norms of law; the latter supports multiple legal patterns, adheres to the de-centralization of the order of state law, and emphasizes the facts of law. Generally, the study of legal pluralism is normally under the jurisprudence tradition with the method thereof. Scholars interpret the legal pluralism as a normative pluralism, or a norm and system with legal effect which is separated from the compulsory machinery of the state. According to B. Tamanaha, law has dual meanings of "confirmation and implementation of norms" and "specific types of social arrangements" (the latter belongs to normative order). Similarly, W. Twining states that legal pluralism is only one kind of normative pluralism, implying the non-central status of the state, while at the same time, it exists how to delimit boundary of legal phenomena and non-legal presences and how to distinguish the large variety of legal orders, systems, traditions and cultures conceptually.

\section{ChinA MaInLAND RESEARCh Status}

Chinese domestic scholars have not done much research on legal pluralism, if any, mainly in the field of legal science. Yang has analyzed and discussed the research path, dilemma and outlet of legal pluralism (Yang Jingzhe, 2013). Yang also have pointed out that the Triple Dilemma of legal pluralism development, "integration", "positioning" and "demarcation" originated from the separation of legal and social disciplines from the norms of legal pluralism in the

\footnotetext{
* Fund: 2018 Southwest University of Political Science and Law "Legal Translation Research under Legal Pluralism", school-level project, project number: 2018XZQN-50. And Southwest University of Political Science and Law Online Course "Legal English", Project number: $2018 Z X B 24$.
} 
Chinese context. As well as analyzed the evolution of legal pluralism and its institutional background (Yang Jingzhe, 2015). Some scholars studied the impact of the emergence and development of legal pluralism on the development of the rule of law in China (Zhang Dezhao, 2013) or studied the new development of legal pluralism theory in China (Zhang Jun, 2010). Some scholars borrowed the theory of Legal Pluralism to conduct interdisciplinary research by combining the concept, value and contemporary significance with criminal law, and put the concept of legal pluralism into practice.(Chen Xingliang, Zhou Guangquan, 1996), or diverge research on the legal pluralism embodied in the concept of sports law (Xiang Huiying, Tan Xiaoyong, Jiangxi, 2015). At present, most of the studies on legal pluralism are confined to the field of law, and there are few studies on the theory of legal pluralism and legal translation. Among the western academics, promoted by Gunther Teubner's "non-state law" and "global law", scholars like Snyder first proposed "global legal pluralism" for the global economic network. This theory has gradually expanded from the economic field to other fields, and has been widely used by scholars as a cross-cultural research method. At the same time, can we borrow legal pluralism to explain and assist the understanding of specific legal concepts in the field of legal English other than that in the traditional law disciplines?

\section{The EnLightenment of Legal PluRAlism on Legal EngLish ResEARCH}

The enlightenment of legal pluralism on the study of legal English can be explored in many aspects. On the basis of the interdisciplinary study of legal pluralism, it can be applied to the study of legal translation, legal linguistics and judicial investigation of legal language by analyzing the schools of legal pluralism theory and making use of the frontier research results of legal theories. It has strong theoretical innovation and practicability, and exploring how the theory can be used to solve the legal concepts dilemma in understanding during legal translation, tackling the issues concerning specific cross-cultural legal language problems, and declassifying the language dilemma in judicial practice.

First, from the perspective of legal pluralism theory, the research objects of legal English are: basic legal pluralism theory, legal text, translation theory, linguistic theory, linguistic evidence in judicial practice, etc. The theoretical framework of the study may include the following aspects:

Second, evolution path of legal pluralism theory. This perspective mainly analyses the origin and extension of the concepts of legal pluralism, and combines the advanced theoretical achievements both in China and overseas to construct and improve the cohesive framework between legal pluralism and legal translation theory.

Third, the generating logic of cross-cultural legal culture system under the theory of legal pluralism. Firstly, from the perspective of legal culture, it analyses various conflicts of legal culture in cross-culture, traces back to the logic of the formation of legal culture system from various manifestations of conflicts of legal culture, and demonstrates the inevitability and contingency of its existence.

Fourth, cultural turn under the legal pluralism. To clarify the possible translation dilemmas in legal translation, combining with specific translation theory, then constructing a new mechanism to solve the conflicts of legal culture with the cultural turn as the main research paradigm.

Fifth, the strategies of legal translation under the theory of legal pluralism. On the basis of the above analysis, enforcing the application of cross-cultural cultural turn in the field of legal translation, formulating corresponding regulations on legal cultural conflicts, and finally proposing legal translation strategies to solve the translation dilemma under the theory of legal pluralism.

Of course, there are also some key and difficult points in this study. Takes the study of legal translation as an example, the problems may exist as following: First, an analysis of the current situation of cross-cultural legal culture in the context of legal pluralism. To sort out and summarize the relevant theoretical research in the relevant academic circle, then find out the similarities and differences of legal culture in different countries, and analyze the reasons. Second, the evolution of legal translation theory under legal pluralism. Combining the relevant theories of legal pluralism with traditional translation theories, locating the specific problems during the process of legal translation and the predicament of "difficult to translate" and "untranslatable", and extracting practical and operable methods. Third, the strategies of legal translation under the theory of legal pluralism. It contains the detailed methodologies concerning application of legal pluralism into the interdisciplinary research and solutions of the practical dilemmas in the legal translation, and feasible translation strategies.

\section{The Innovative Points of the Theory of Legal Pluralism in the Study of Legal English}

First, the application of legal pluralism in the field of legal English is innovative. The theoretical exploration of legal pluralism has attracted expanded attention among the western academics. Legal English, as an important branch of ESP, must be supported by the development of legal theory and English theory, and take it as the backbone. This interdisciplinary study will systematically study the development process of legal pluralism theory, as well as the possible cultural conflicts and their manifestations are the combination of theory and practice. The application of legal pluralism in legal English is an innovative application of the frontier theory.

Second, the innovation of legal English research paradigm under the theory of legal pluralism. At present, most of the studies on English translation, legal linguistics and judicial language are limited to the traditional theoretical research, while the interdisciplinary angle provided the combination of theories in the law field, and be applicable to the 
theoretical research of legal translation, legal linguistics and judicial language, breaking through the traditional research paradigm limits.

Thirdly, the comprehensive application of interdisciplinary. Breakthrough is made by no longer constrain the research methods in a certain discipline. It integrates systematic and interdisciplinary research, combines the knowledge of law, sociology, linguistics, translation and other disciplines into one, and carries out research methods such as text analysis and field investigation.

\section{Legal TRANSLATION IN THE SOCIAL SySTEM THEORY}

Under Luhmann's social system theory of law, it claims that there should be a uniform judicial adjudication mechanism, that is, the dual code of "legal/illegal" acts on the whole legal system, while Gunther Teubner believes that different departmental laws can have different judicial adjudication mechanisms, which will inevitably lead to conflicts between different legal systems. Relying on Teubner's view, the social system theory of law can be used to solve the problems brought about by the pluralism of law, then to solve the problems in legal translation, and to identify non-state laws without abandoning the basis of distinguishing law from other parts of society. It is more like denying the existence of law to distinguish the definition of law only by the understanding of officials or by the behavior of a person who enforces punishment. For example, in the post-colonial period, the application of uniform standards in central areas had advantages, so people gradually evolved from a consistent practice to customary law. In contrast, the functionalist theory regards law as a way to resolve disputes, which blurs the boundaries between law and society. How does the code operate in different legal and cultural contexts? If the "legal/illegal" code only has a semantic difference, it will still run in the traditional way. However, if such communication only exists in a specific context, and the specific communication is a part of the system, the use of code in the system is very important for the formation of specific communication.

Unlike the multi-word substitution of the word "law", the "legal/illegal" code is used in many languages. For example, the word "law" can be translated into languages as: loi, droit, recth, gesetz, and in these corresponding languages "lawful/unlawful" appears in the form of homology as "legal/illegal". If the target language lacks corresponding phrases, can legal codes be identified by the translation alone, even without the use of "legal/illegal" codes? For example, in some specific cultures in Chinese minority world, the legal origin of minority nationalities is called "governing the exogenous world", that is, kinship organizations of geographical and consanguineous origins are more binding on the people than that of the legal orders. There are some form of regional adjudication assembly still exists among minority nationalities in remote areas of China, like in Wa minority village, the code of "legal/illegal" may appear here as "compliance/non-compliance" code, while outside the country, the code of "legal/illegal" related to Italian Mafia may be replaced by "honour/dishonour" code. Teubner's theory refers this phenomenon as the conflict between "law and social norms", that is, between the state law and honor of the family or morals of the tribe.

The emergence of "legal/illegal" codes in different languages and the binary differences reflected in their application just reflect the problems in legal translation. That is to say, in the face of two languages with different etymologies, how can translators determine the rationality of adopting "legal/illegal" codes? What guides translators to find equivalents in source and target languages? From the beginning of Saussure, people began to realize the semantics of symbol generation in language and its related linguistic relations. From Wittgenstein's theory, people found that this relationship is not based on the use of language, but on rules. Semantic translation from one language to another is often difficult to achieve accuracy, because certain words are inextricably linked in different languages, sometimes even if the same phrase is in the same sentence pattern, it is not consistent in different languages. The social system theory of law replaces this tool by replacing the supply code with function or structure, and the translation of legal code (legal/illegal) should conform to certain norms. One can not only focus on how to find the corresponding "legal / illegal" phrase in another language, but should explore how the code is generated in the system. Functional equivalence is only a by-product attached to the running of system code, and it is not a determinant of coding possibilities.

In addition, sometimes a similar dilemma arises even if the target language comes from the same source. The world "legal" is is a Latin word that originated in the 15 th century and means "related to law". If legality refers to "law-related, legal, lawful", then "not legal" is naturally "law-unrelated, non-legal, illegal". Is it more straightforward to translate "legal/illegal" into "law/not law"?

\section{ViI. Evolution of Legal TRAnSLATiOn Model}

The system code has positive code and negative code, and its operation will makes its structure (program) more stable, rather than being determined by the program. As we all known, the legal system is not entirely equivalent to state law. State Law refers to a stage of the legal system in the development of modern society, not the ultimate stage. The central position of national legislation in the modern legal system forms the self-description of law or jurisprudence, which makes the communication of law more abstract. However, the system theory does not need to determine whether communication originates at a certain period in the evolution of the legal system, whether the self-description of the legal system is a whole or a core part, or whether the possibility of the future is coded as "positive/negative" (or 
legal/illegal) within the system. Generally speaking, attributing the law to state law is a negation of the existence of law, not to mention in the context of the current expanding cross-border legal communication.

How do we recognize that such transnational communication is legal, not scientific, medical or even economic? In the context of the legal system, we should not only distinguish "legal/illegal" from specific semantics, but also regard it as a developing and evolving system. Through the application of code, especially on the positive/negative distinction, we can determine the key characteristics of the advance procedure. Or through the application of legal code in communication, it can be considered that the communication is the continuation of the legal system. By identifying the multiple forms and sources of law, and by using legal codes rather than absolute semantics, it provides a method for legal observation and jurisprudence research. Systematic theory operates in the legal system in this way and can be distinguished from other social subsystems in different societies. This does not separate the law from society through the application of definitions or concepts, and the coding process enables communication within the system to be established. The separation of social subsystems is a characteristic of modern society. On the one hand, we try to make law equal to legal rules, norms or social commitments. On the other hand, we can expand the scope of legal observation. It is difficult to explain the difference of behavior (performance or function) in different social structures or the value attached to it. One is the duplication of attributes among different subsystems, and the other is the dilemma of explaining the contradictions among these attributes.

Therefore, system theory no longer pays attention to the basic or necessary attributes in the system, but regards these attributes as programs to guide or fix (rather than determine) the application of system code. With the shift of emphasis from procedure to code, the basis of our study of law should be changed to that law does not exist only in state law, but state law can provide a general paradigm for other non-state forms of law. Based on these advantages, we can draw a basic methodology to solve the problem of language translation. Similar to the previous theoretical arguments on translation, there are no specific rules in legal translation under legal pluralism, just as there are no rules to determine the use of language. Codes in different cultures convey linguistic information in context. Such successful communication is based on ordinary text decoding to generate common semantics for information exchange.

This means that language is not only embedded in culture, but also a form of cultural expression. Translation is the re-creation and expression of a culture in a new language. In legal translation, for example, the term "law". In language, it refers to the conditional procedure for the application of legal codes in a particular legal system, and it can also refer to the conditional procedure for the application of legal codes in other systems. Recognition of legal systems is linked by the application of ordinary codes, not economic, scientific, religious or moral, but at the same time can produce certain norms, so the legal system can be regarded as abstract but not anxious for common culture. Based on this, the study only focuses on the actual use of code, how the program can produce extremely useful descriptions through secondary observation. Of course, this interpretation can not provide an absolute answer to the problem of legal pluralism, but it provides a general theoretical perspective, not based on the general concept of law, but on the understanding of sociology. For example, "collateral attack", although according to the res judicata jurisprudence of the United States, the request for invalid confirmation once a judgment is concluded is generally not supported. However, the basic requirement of res judicata is "jurisdiction of adjudication", due process and other problems. On the basis of proper respect for the jurisdictional reasons of other states' judgments given by the courts of the states that have recognized the judgments, the parties who advocate opposite opinions in the original judgment bear the correct and appropriate burden of proof, and then judge the problem through the correct procedure. The translation of the term "collateral attack" has different versions in Chinese, such as indirect attack, indirect re-suit, indirect objection, ex post facto attack and parallel review can be found in the current literature. In the absence of corresponding judicial level in Chinese, only based on the understanding of the Anglo-American legal system, to give a relatively appropriate comment, "indirect re-suit" may be more appropriate.

\section{CONCLUSION}

Modern Chinese legal culture is an open system. Diversity is the essence of legal culture. Any legal culture is bound to be national and epochal, and develops continuously with the change of material production mode and the change of the times. With the further expansion of the openness of the country, the reconstruction of legal culture has naturally entered a new stage. Pluralists generally believe that religion or customary law is a part of life, and it is also reflected in systematic theory. This process also means that the existing customs of local communities (people) are in conflict with the rules and practices of the national legal system. This kind of conflict not only means whether the state law can regulate the local customs, but also means whether such special groups can stand in the modern society with "habitual lifestyle". The application of legal code makes people realize the multiple types and sources of law, and provides a way of legal observation and exploration, rather than to solidify the semantics.

\section{REFERENCES}

[1] Benjamin N. Cardozo. (2007). The nature of the judicial process, Su Li translate, The Commercial Press: Beijing, pp. 45.

[2] B. Tamanaha. (2008). Understanding Legal Pluralism: Past to Present, Local to Global, 30 Sydney Law Review 2008 , pp. 397-409.

[3] B. Tamanaha. (2011). The Rule of Law and Legal Pluralism in Development, 3 Hague Journal on the Rule of Law 2011, 
pp.1-17.

[4] Dennis Lloyd. (2005). The idea of law, Zhang Maobai translate, New Star Press: Beijing, pp.135.

[5] Edgar Bodenheimer. (2017). Deng Zhenglai translate, Jurisprudence: the philosophy and methods of the law, China University of Political Science and Law press: Beijing, pp.419.

[6] Gao Hongjun. (2007). Semantics, context and Chinese issues of legal culture, China Legal Science, 4, pp.23-38.

[7] Geertz, Clifford (1973). The Interpretation of cultures. Selected Essays, Basic Books Publishers: New York, p. 89.

[8] Harry W. Jones. (1963). The creative power and function of law in historical perspective, 17 Vanderbilt Law Review 135, pp. 139.

[9] G. Teubner. (1997). Global Bukowina: Legal Pluralism in the World Society, in Gunther Teubner (ed.), Global Law without a State, Aldershot: Dartmouth, 3.

[10] Gunther Teubner. (2015). Hanlong Ji translate, Law and Law Practice in the Context of Social Theory, Jiaotong University Law, No. 3, pp.71-85.

[11] Henry. W. Ehrmann. (1990). Comparative legal culture, He Wei Fang, Gao Hongjun translate, SDX Joint Publishing Company: Beijing, pp.7.

[12] Paul Schiff Berman. (2012). Global Legal Pluralism: A Jurisprudence of Law Beyond Borders, Cambridge University Press: Cambridge.

[13] Wendy A. Adams. (2016). Popular Culture and Legal Pluralism: Narrative as Law, Ashgate Publishing Limited: London.

[14] W.Twining. (2010). Normative and Legal Pluralism: A Global Perspective, 20 Duke Journal of Comparative and International Law 2010, pp.488-489.

[15] Yang Jingzhe. (2013). Legal pluralism: track, dilemma and outlet. Science of Law (Journal of Northwest University of Political Science and Law), 02, pp.3-10.

Xia Dai, Master in Psycholinguistics (University of York, U.K.), Ph.D. in Laws (Law School, Chongqing University, China), now a lecturer at the School of Foreign Languages, Southwest University of Political Science \& Law, China. She specializes in second language acquisition, legal languages and legal translation. 